\title{
Por que não avança a avaliação ambiental estratégica no Brasil?
}

\author{
LUIS ENRIQUE SÁNCHEZ ${ }^{I}$
}

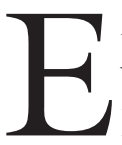

M DEZEMBRo de 2008, o Instituto de Estudos Avançados da USP promoveu um debate intitulado "Rumos da Avaliação Ambiental Estratégica no

Brasil", que teve minha moderação. Participaram três debatedores, dois com posições importantes respectivamente no governo federal e no estadual de São Paulo, e o terceiro com experiência na área de planejamento.

Naquela ocasião, ainda que sabedores das dificuldades e obstáculos para a prática da Avaliação Ambiental Estratégica (AAE) no Brasil, havia certo tom de otimismo. A AAE poderia ser adotada por setores mais progressistas e modernos dos governos e contribuiria para melhorar as práticas de planejamento, inserindo talvez definitivamente o meio ambiente como elemento estratégico na formulação de políticas públicas, planos e programas governamentais.

No início dos anos 2000, iniciativas de avaliação ambiental estratégica se multiplicaram no Brasil. Exploração de petróleo e gás no litoral sul da Bahia, implantação de um polo minerossiderúrgico às margens do Pantanal e um plano de aproveitamento do potencial hidrelétrico remanescente em Minas Gerais são exemplos de tais iniciativas.

Uma característica comum era seu caráter "voluntário", no sentido de que essas iniciativas não foram apresentadas como resposta ou em atendimento de alguma exigência legal ou requisito de instituição financeira - como é o caso do estudo de impacto ambiental necessário para o licenciamento de obras ou atividades potencialmente causadoras de significativa degradação ambiental -, mas como iniciativas de planejamento.

Com base nessa experiência prática, a pesquisa acadêmica avançou, e encontrou evidências - que se somam à percepção dos profissionais do setor - de total ineficácia da AAE tal como praticada no Brasil. Um exemplo emblemático é o trabalho de Bastos (2015), que encontrou que nenhuma das recomendações da AAE do Programa de Geração Hidrelétrica de Minas Gerais, concluídas em 2007, foi adotada pelo governo estadual. Nem mesmo a sequência recomendada para licenciamento ambiental de pequenas centrais hidrelétricas, que daria preferência a projetos de menor impacto, foi seguida. Aliás, como comprovou a autora, os estudos de impacto ambiental de projetos hidrelétricos submetidos a licenciamento após a conclusão da $\mathrm{AAE}$ sequer a mencionam. 
Partindo do texto base preparado para o debate do IEA, ${ }^{1}$ nunca publicado exceto no site do próprio Instituto, este artigo revisita a AAE no Brasil, fazendo um breve histórico de iniciativas governamentais voltadas para sua institucionalização e reafirma sua potencial contribuição para uma melhor governança ambiental, ao mesmo tempo que procura identificar os principais obstáculos para sua adoção no Brasil. A primeira seção apresenta conceitos e definições, seguindo-se uma exposição sobre a utilidade e as funções da AAE. A terceira seção trata brevemente da difusão internacional desse instrumento, ao passo que na quarta seção é feito um histórico sucinto da AAE no Brasil. Na quinta seção discutem-se algumas perspectivas da AAE, seguidas de conclusões, na última seção.

\section{Conceitos}

A Avaliação Ambiental Estratégica (AAE) é o nome que se dá a todas as formas de avaliação de impacto de ações mais amplas que projetos individuais. Tipicamente, a AAE refere-se à avaliação das consequências ambientais de Políticas, Planos e/ou Programas (PPP), em geral no âmbito de iniciativas governamentais, embora possa também ser aplicada em organizações privadas.

Trata-se, bem entendido, de avaliação prévia, equivalente, em certa medida, àquela feita para projetos, obras ou atividades. Entretanto, o grande potencial da AAE está em influenciar a própria formulação de PPP, e não em fazer uma avaliação voltada apenas a mitigar alguns efeitos adversos. Não se trata, portanto, de um "teste" para aprovação ou legitimação de PPP, nem da mera verificação de consequências após sua formulação.

Uma das primeiras definições de AAE é:

processo formal, sistemático e abrangente de avaliar os impactos ambientais de uma política, plano ou programa e de suas alternativas, incluindo a preparação de um relatório contendo as conclusões da avaliação, usando-as em um processo decisório publicamente responsável (publicly accountable). (Thérivel et al., 1992, p.19-20)

Tal formulação se espelha na avaliação de impactos de projetos, uma das origens da AAE. Com avanços tanto na prática como no plano conceitual, outras definições foram propostas, como a seguinte:

conjunto de abordagens analíticas e participativas destinadas a integrar considerações ambientais ao nível das políticas, planos e programas, bem como a avaliar as interligações com as consequências econômicas e sociais. (OCDE, 2012, p.17)

Essa definição atribui à AAE um papel proativo, de trazer as considerações ambientais ao primeiro plano dos critérios decisórios. Na literatura, encontram-se diversas categorizações da AAE. Uma delas classifica as abordagens como "centrada nos impactos" de uma PPP ou como "centrada nos objetivos". Enquanto a primeira buscaria principalmente identificar, prevenir e mitigar efeitos adversos de decisões estratégicas, a última teria como foco integrar preocupa- 
ções ambientais no processo de formulação de uma PPP, identificando objetivos ambientais e de sustentabilidade de mesma importância que os demais objetivos. $\mathrm{O}$ Quadro 1 resume as principais funções usualmente atribuídas à AAE.

\section{Quadro l - Funções da Avaliação Ambiental Estratégica}

- Identificar e avaliar as consequências de uma decisão (estratégica) e de suas alternativas antes que ela seja tomada;

- Inserir a dimensão ambiental e de sustentabilidade no processo de tomada de decisão;

- Formalizar, sistematizar, documentar e informar uma decisão (estratégica) a ser tomada;

- Criar oportunidades de desenvolvimento que contribuam para a recuperação da qualidade ambiental, prevenção de riscos e melhoria da qualidade de vida das presentes e futuras gerações.

Assim, uma questão de fundo para a prática da AAE é definir se ela se limita a avaliar os impactos de PPP ou visa principalmente influenciar a elaboração de PPP, o que é também chamado, respectivamente, de abordagens "reativa" e "proativa". Dependendo do entendimento que se tenha da AAE e seus papéis, o desenho institucional para sua prática e a eventual legislação terão características bem diferentes. Minha posição é que a AAE deve ser usada ativamente na formulação de políticas, planos e programas, assim como na própria definição dos objetivos estratégicos de cada PPP.

\section{Da necessidade da avaliação ambiental estratégica}

A AAE tem se firmado internacionalmente como ferramenta de planejamento devido a duas ordens de fatores: (i) os impactos socioambientais adversos de PPP e (ii) as limitações inerentes à avaliação de impactos ambientais de projetos.

\section{Impactos adversos de politicas, planos e programas}

Impactos socioambientais negativos decorrem como efeitos colaterais de inúmeras políticas públicas, sejam elas macroeconômicas, setoriais, sejam as de transportes e de energia, ou mesmo políticas de inclusão social. O relatório da comissão Brundtland aponta essa relação:

A capacidade de escolher políticas sustentáveis requer que as dimensões ecológicas das políticas sejam consideradas ao mesmo tempo em que as econômicas [...] e outras dimensões - nas mesmas agendas e nas mesmas instituições. Este é o principal desafio institucional dos anos 1990. (WCED, 1987, p.313)

Sem nenhuma dúvida, esse desafio institucional continua atualíssimo em 2016. Há inúmeros exemplos de decisões governamentais relativas a políticas, planos ou programas que causaram ou têm causado significativos impactos socioambientais (ou mesmo econômicos) adversos. Um caso bem estudado é o das 
políticas do governo federal brasileiro relativas à ocupação da Amazônia durante as décadas de 1970 e 1980. De acordo com a visão governamental dominante naquela época, importavam pouco os custos e os benefícios da transferência de grandes contingentes populacionais vindos de outras regiões do país. O que determinava essa orientação eram razões de ordem geopolítica fundamentadas na percepção de setores dominantes dentro do aparelho governamental, de que países estrangeiros estariam planejando a ocupação da região. Uma das políticas públicas que fundamentava esta orientação governamental era a concessão de benefícios fiscais para empresas e cidadãos que promovessem a derrubada da floresta.

Os incentivos fiscais concedidos incluíam:

- abatimento de até $50 \%$ no imposto de renda para investimentos em projetos localizados na Amazônia Legal;

- crédito agrícola subsidiado.

A maioria dos projetos aprovados era do setor agropecuário, e requeria a derrubada da floresta. Já o montante de crédito agrícola aplicado na Amazônia foi multiplicado por dez entre 1974 e 1980 (Mahar, 1988, p.17), graças ao emprego de taxas de juros mais baixas que aquelas praticadas em outras regiões do país, o que "indubitavelmente facilitou a aquisição e o desmatamento de grandes parcelas de terra na Amazônia, particularmente na segunda metade dos anos de 1970" (ibidem, p.18). Ironicamente, a súbita e drástica redução do volume de crédito, a partir de 1980, também levou a mais degradação, uma vez que muitos agricultores abandonaram culturas intensivas em capital e dependentes de insumos industrializados, passando a praticar a tradicional derrubada e queima.

Outras formas de isenção fiscal também redundaram em incentivos à derrubada da floresta. É o caso do Programa Grande Carajás, cujos incentivos fiscais favoreceram a implantação de várias indústrias de ferro-gusa, que consumiam carvão vegetal proveniente de florestas nativas, assim como a instalação de várias madeireiras, outra fonte evidente de degradação da floresta (Biswanger, 1989, p.12).

Por outro lado, também a política agrícola favorecia o uso insustentável da floresta. O Instituto Nacional de Colonização e Reforma Agrária concedia títulos de propriedade para aqueles que demonstrassem ter realizado benfeitorias. A derrubada da floresta era entendida como benfeitoria. Dessa forma, usos da terra que mantivessem a floresta em pé, como produção de castanhas ou coleta de látex, eram claramente desfavorecidos. A política agrária tinha ainda outro efeito perverso, pois uma vez assegurada a posse da terra, o lote podia ser vendido e o agricultor procurava novas terras para reiniciar o processo (Mahar, 1988, p. 27).

Também políticas voltadas para outras regiões do país tiveram reflexos na Amazônia. Biswanger $(1989$, p.4) aponta os efeitos da baixa taxação sobre os rendimentos agrícolas que, ao levar ao aumento do preço da terra e à concentração da propriedade agrária, motivou muitos pequenos agricultores do centro-sul a se deslocar para a fronteira agrícola do centro-oeste e da Amazônia. 
Da mesma forma que os efeitos deletérios de obras de grande impacto ambiental foram evidenciados através de estudos realizados depois de concluídos os projetos, também para programas e políticas, avaliações ex post têm demonstrado a ocorrência de impactos negativos. Por exemplo, Wathern et al. (1987) mostraram que os resultados de um programa do governo britânico e da então denominada Comunidade Econômica Europeia para proteção de paisagens e populações tradicionais de áreas montanhosas foram contrários aos pretendidos. Esse programa incluía subsídios para pastoreio e ajudas de capital para investimentos e melhorias em propriedades rurais, e representava a continuidade de um programa nacional implementado desde a década de 1940. A avaliação dos resultados do programa constatou uma redução substancial das áreas de vegetação seminatural, ao mesmo tempo que cresciam o total de ajudas alocadas e o rebanho ovino. $\mathrm{O}$ pretendido apoio às populações tradicionais não logrou resultados: o número de propriedades rurais diminuiu, assim como a quantidade de fazendeiros, enquanto o tamanho médio das fazendas cresceu, ou seja, houve uma concentração da atividade de criação, que passou a ser realizada por um número cada vez menor de pessoas. Além desses impactos, os autores apontam que sítios arqueológicos foram afetados e também ocorreram impactos adversos não monitorados sobre a fauna silvestre e a qualidade das águas.

Políticas de incentivos fiscais ou subsídios econômicos que não incluam salvaguardas ambientais frequentemente causam degradação ambiental, conforme documentado, entre outros estudos, por Roodman (1996), que aponta os efeitos deletérios de subsídios explícitos ou ocultos concedidos por vários países, e Gorelick (1998), que critica a alocação de recursos e os subsídios dados ao setor de transportes. Em diferentes partes do mundo, o setor de energia é um dos que mais têm se beneficiado desses incentivos. No Brasil, a política de apoio à produção de carvão mineral implementada a partir dos choques dos preços do petróleo da década de 1970, política esta que vigorou até o início dos anos de 1990, levou a um grande aumento na produção da bacia carbonífera de Santa Catarina. Entretanto, a falta de medidas de proteção ambiental, especialmente de controle de poluição, causou sérios problemas de contaminação de solos, águas superficiais e subterrâneas, diminuição da produção agrícola e piscícola e diversos outros impactos, incluindo danos à saúde humana. $\mathrm{O}$ custo das ações de recuperação ambiental, uma medida mínima do dano, foi estimado em pelo menos US\$ 112 milhões (Sánchez et al., 1994).

\section{Limites da avaliação de impacto ambiental de projetos}

As limitações naturais do Estudo de Impacto Ambiental (EIA) constituem outro motivador da AAE. As dificuldades, mesmo dos melhores EIA, de analisar com profundidade alternativas tecnológicas e de localização, de levar em conta satisfatoriamente os impactos cumulativos e os impactos indiretos são inerentes a essa forma de avaliação de impacto ambiental.

As avaliações individuais de projetos frequentemente suscitam contro- 
vérsias públicas nas quais os questionamentos se referem a decisões tomadas anteriormente ou decorrem da mera continuidade de políticas já estabelecidas e cujas consequências ambientais já são conhecidas. A avaliação de projetos é feita sem levar em conta boa parte dos impactos cumulativos ou sinergísticos, ou alguns dos mais importantes impactos indiretos, cuja mitigação requer ação governamental coordenada ou mesmo novas leis e instituições.

Assim, um dos mais significativos efeitos indiretos das hidrovias do centro-oeste brasileiro, incluindo a hidrovia do Mercosul (Paraná-Paraguai) e a hidrovia Araguaia-Tocantins, projetos propostos pelo governo federal brasileiro em meados da década de 1990, é acelerar a ocupação da região, intensificando o desmatamento dos remanescentes de vegetação nativa e a pressão sobre as terras indígenas, decorrentes da expansão da monocultura da soja, por sua vez facilitada pela existência de novos e mais baratos meios de transporte. Trata-se de impactos indiretos cujos equacionamento e gestão estão muito além das atribuições e competências institucionais do proponente desses projetos, empresas públicas dependentes do Ministério dos Transportes. Uma abordagem "estratégica" facilmente identificaria os principais problemas suscitados por esses modais de transporte nessa região, possibilitando a discussão e o eventual desenho de soluções antes que cada projeto individual fosse apresentado para avaliação e licenciamento. Os estudos de impacto ambiental de cada projeto poderiam então se concentrar em identificar, prever e avaliar seus impactos específicos e definir medidas de gestão compatíveis com as capacidades institucionais do promotor do projeto.

Impactos de grande abrangência espacial, inclusive impactos globais, também não são de fácil tratamento nos estudos de impacto de projetos. Emissões de $\mathrm{CO}_{2}$ e outros gases causadores do efeito estufa podem ser facilmente menosprezadas na avaliação de uma fábrica de cimento ou de uma usina termoelétrica, em face de impactos mais importantes para o ambiente local, como a deterioração da qualidade do ar devido às emissões de óxidos de nitrogênio e de enxofre.

A análise de alternativas é também limitada nas avaliações de projetos (Steinemann, 2001). Se uma empresa solicita uma licença para construir uma usina termoelétrica a gás, não há como exigir, realisticamente, que o estudo de impacto ambiental considere outras opções de geração com nível similar de detalhe. Normalmente os EIA são feitos quando o projeto de engenharia está suficientemente delineado (normalmente um projeto básico) e quando as avaliações econômicas já indicam sua viabilidade. Isso significa que recursos já foram despendidos na preparação do projeto e em sua avaliação econômica, de forma que o retorno a uma condição "estratégica" de análise de opções representa um questionamento de decisões já tomadas. Não que esse questionamento não possa ou não deva ser formulado, mas é justamente durante uma avaliação ambiental estratégica o melhor momento para fazê-lo; antes, portanto, da escolha de opções tecnológicas e da decisão sobre a localização dos projetos. 
Finalmente, outro limite da avaliação individual de projetos é a cultura técnica e as atribuições legais de departamentos governamentais. Muitos projetos têm origem em órgãos ou empresas especializados em determinada opção tecnológica. Um departamento governamental de estradas de rodagem não tem por missão propor uma alternativa ferroviária e frequentemente nem tem competência técnica para formular esse tipo de alternativa. Inútil, portanto, pensar em exigir que esse departamento considere a alternativa de transporte ferroviário cada vez que apresenta a proposta de uma nova rodovia. É, portanto, em outro nível burocrático que políticas de transporte devem ser formuladas, discutidas e avaliadas, inclusive quanto aos seus efeitos ambientais.

\section{Disseminação internacional da AAE}

Pode-se argumentar que a Avaliação de Impacto Ambiental (AIA) já nasceu estratégica, na medida em que a National Environmental Policy Act dos Estados Unidos - a lei de 1969 que primeiro a institucionalizou - demanda a avaliação prévia de impactos de quaisquer ações que possam afetar significativamente a qualidade do ambiente humano, uma vez que o termo ações é interpretado como incluindo não somente obras ou atividades, mas também outras iniciativas governamentais como planos e programas. Tal entendimento deu origem, naquele país, ao termo "estudo de impacto ambiental programático" para designar os estudos de impacto ambiental feitos para tais iniciativas.

Foi, no entanto, somente no início da década de 1990 que a AAE passou a se firmar como um campo de atividades que se distingue da AIA de projetos, graças, em grande parte, a avanços observados em países como a Holanda, que inseriu a AAE em seu ordenamento jurídico e em práticas de governo em 1987, antes de sua adoção pela União Europeia (2001).

A prática da $\mathrm{AAE}$ tem se expandido internacionalmente. Em vários países, particularmente na Europa, a AAE foi institucionalizada e é objeto de leis e regulamentos (Dalal-Clayton; Sadler, 2004; Kläne; Albrecht, 2005). Sua expansão vem sendo promovida por países doadores de recursos para o desenvolvimento no âmbito do Comitê de Ajuda ao Desenvolvimento da Organização para a Cooperação e o Desenvolvimento Econômico (OCDE) (Sánchez; Croal, 2012), posição que os alinha à política que adotada por alguns bancos multilaterais de desenvolvimento (Ahmed; Mercier; Verheem, 2005). Por outro lado, certos países em desenvolvimento já avançaram bastante em sua própria capacitação em matéria de AAE, notadamente a África do Sul (Dalal-Clayton; Sadler, 2004; Retief, 2007). A China modificou sua legislação em 2009 tornando obrigatória a avaliação ambiental de planos governamentais. Deve-se ainda mencionar que a AAE também é promovida como um meio de se atingir os objetivos de convenções internacionais, como a Convenção sobre a Diversidade Biológica (Slootweg et al., 2006).

Metodologias, avaliações críticas, conceitualizações e guias práticos são hoje abundantes e permitem um bom entendimento do potencial, do alcance, das limitações e das condições para efetividade da AAE. 
Iniciativas visando consolidar o conhecimento teórico-prático adquirido nessa área já se observam desde o início da década de 1990 (Thérivel et al., 1992), e hoje em dia se desdobram em guias, livros texto e significativo volume de artigos científicos (Tetlow; Hanusch, 2012). Tema recorrente - e fundamental - é a efetividade da AAE, em particular na dimensão substantiva, isto é, sua real influência sobre processos decisórios, a "medida" de seu sucesso.

\section{AAE no Brasil: um breve apanhado}

Debatida em restritos círculos acadêmicos e governamentais no início dos anos de 1990, avaliação ambiental estratégica é hoje um conceito familiar aos profissionais e pesquisadores de avaliação de impacto e a alguns formuladores de políticas, mas seu significado e principalmente sua forma de aplicação estão longe de ser consensuais. Convém, portanto, fazer um breve histórico sobre seu emprego no Brasil e algumas iniciativas de institucionalização.

Uma primeira tentativa de institucionalizar a AAE foi feita em âmbito estadual, em São Paulo, em 1994, como resultado de um trabalho de reforma e atualização dos procedimentos de AIA realizados pelo Conselho Estadual do Meio Ambiente (Consema). Na ocasião, a Secretaria do Meio Ambiente aprovou uma resolução criando uma comissão de $\mathrm{AAE}$, mas os trabalhos não tiveram resultados práticos, pois não foi possível envolver outras secretarias ou não houve apoio político para tal e nenhum efeito prático foi observado.

Ainda no final dessa década, no plano federal, um estudo encomendado pelo Ministério do Meio Ambiente (MMA) recomendou que a AAE no Brasil fosse implementada por meio de legislação, mas sem atrelar a elaboração de estudos de $\mathrm{AAE}$ ao licenciamento ambiental, em concordância com a opinião dos poucos estudiosos do assunto, como Egler (2001). O estudo também recomendou que a AAE fosse aplicada ao Plano Plurianual do governo federal (MMA, 2002). O Ministério desenvolveu algumas iniciativas internas, como organizar seminários e promover cursos de capacitação em AAE. Em 2004, foram realizadas uma oficina e um evento internacional, e, no período 2006-2007, um curso de especialização voltado para funcionários de órgãos federais e estaduais da região do Pantanal.

Deve-se mencionar que importante impulso à expansão da AAE decorre de decisão do Tribunal de Contas da União (acórdão 464/2004) que, provocado pelo MMA, executou auditoria de natureza operacional e análise de aplicabilidade da AAE pelo governo federal. O acórdão recomenda a adoção da AAE na elaboração do Plano Plurianual e no planejamento de políticas, planos e programas setoriais e atuação do MMA na divulgação do instrumento e capacitação para seu uso.

No Congresso Nacional, pode-se mencionar o Projeto de Lei 2072/2003, apresentado à Câmara dos Deputados, que propunha alteração da Lei 6938/81, da Política Nacional do Meio Ambiente, introduzindo a obrigatoriedade AAE de PPP. Outros projetos se seguiram, mas nenhum chegou a votação. Montaño, 
Malvestio e Opermann (2013) listam diversas iniciativas, também em âmbito estadual e municipal, desde 1994.

As iniciativas do MMA tiveram pouco sucesso. A preparação de um "Guia Metodológico para a Prática da AAE”, para o qual foram realizadas oficinas com especialistas externos e uma consulta pública, esta em outubro de 2010, não vingou, possivelmente devido a divergências metodológicas ou sobre conteúdo, assim como não chegou ao final a publicação de um livro conclusivo sobre a experiência na região do Pantanal.

Maior potencial teria outra iniciativa, também sem sucesso: a articulação com outros ministérios para adoção da AAE na formulação de certos planos e programas. Novamente foram envolvidos consultores e especialistas internos e externos, mas em 2014 toda a articulação desmoronou ao não obter suporte da Casa Civil.

A única iniciativa institucionalizada remanescente é a denominada "Avaliação Ambiental de Área Sedimentar”, instituída por meio de portaria interministerial em 2012 e voltada ao setor de petróleo e gás. Tal avaliação deve considerar os recursos em hidrocarbonetos fósseis de uma bacia sedimentar à luz de suas características socioambientais e propor um plano de ação. Os Ministérios de Minas e Energia e Meio Ambiente têm procurado implementar essa ferramenta.

Em mais uma demonstração de que a AAE entra e sai da pauta com certa frequência, exatamente no dia em que concluo este artigo (15 de agosto de 2016), a imprensa informa que o Executivo Federal enviará ao Congresso Nacional proposta de lei que altera o licenciamento ambiental (haja vista projetos de Lei altamente retrógrados apresentados na Câmara e no Senado) e incluirá, em sua proposta, a AAE.

Em paralelo, mais de trinta AAE foram realizadas no país desde 1994. São dois os principais motivadores: exigência de instituições financeiras multilaterais (Pellin et al., 2011) e a perspectiva, da parte de certos empreendedores governamentais e privados, de que a AAE poderia ser um facilitador do licenciamento ambiental de projetos.

$\mathrm{Na}$ falta de uma base de dados centralizada, alguns pesquisadores procuraram mapear o acervo brasileiro de AAE. Teixeira (2008) fez um levantamento preliminar de experiências de AAE no Brasil entre 2002 e 2007, reunindo dez casos. Margato e Sánchez (2014) identificaram 24 casos até 2011 e analisaram o conteúdo de três. Montaño, Malvestio e Opermann (2013) levantaram "cerca de 40" AAE no país. Tais cifras são muito baixas para mais de vinte anos de prática, e contrastam com algumas centenas de tais estudos feitas em alguns países (Montaño et al., 2014) e contrastam com a importância que atingiu a AAE em termos de pesquisa e mesmo como tema de ensino (Ramos et al., 2015).

Há que notar que iniciativas de planejamento não denominadas como avaliações estratégicas, inclusive realizadas durante os anos de 1990, podem apresentar muitas das características que se atribuem à AAE. Uma avaliação integra- 
da (ambiental, econômica, técnica) de um programa de transmissão de energia elétrica entre usinas hidroelétricas planejadas para a bacia Amazônica e os principais centros de carga situados no centro-sul do Brasil foi feita no início dos anos 1990 pela Comissão de Planejamento da Transmissão da Amazônia, coordenada pela Eletrobras, empresa estatal holding do setor elétrico, com participação de várias empresas e entidades (Pires, 1993).

Também o ordenamento da atividade de mineração (principalmente extração de areia para construção civil) em um trecho da planície aluvionar do rio Paraíba do Sul, promovido pela Secretaria de Meio Ambiente do Estado de São Paulo, guarda muitas semelhanças com o processo usual de AAE (identificação e avaliação das consequências da expansão da produção por parte de grande número de agentes, participação pública, propostas de mitigação e influência sobre o processo decisório, na medida em que o licenciamento de novos empreendimentos ou da expansão daqueles existentes deve atender aos requisitos estabelecidos para a região, ao passo que as particularidades de cada empreendimento são analisadas em seu próprio estudo ambiental). Entretanto, essa iniciativa de ordenamento territorial e setorial não foi rotulada como AAE.

Um nítido impulsionador da AAE no Brasil tem sido a dificuldade de licenciamento ambiental de certos grandes projetos, como alguns citados na lista de Teixeira (2008). Um exemplo é o caso do "Rodoanel Metropolitano de São Paulo", uma via expressa perimetral que interliga as principais rodovias que partem da capital. Em face das dificuldades encontradas para o licenciamento ambiental do projeto, o empreendedor (Secretaria Estadual dos Transportes) o retirou da análise então em andamento na Secretaria do Meio Ambiente e preparou um documento intitulado "Avaliação Ambiental Estratégica do Programa Rodoanel", o qual serviu de base para um novo estudo de impacto ambiental de um dos trechos do projeto (Sánchez; Silva-Sánchez, 2008). Nesse caso (como em muitos outros), a AAE teve pouca ou nenhuma influência sobre a decisão do empreendedor e mesmo sobre o licenciamento ambiental.

Dessa foram, em que pesem as tentativas, o Brasil continua sem atender o compromisso firmado quando ratificou a Convenção da Diversidade Biológica, cujo artigo 14 trata da Avaliação de impacto e minimização de impactos negativos:

1. Cada Parte Contratante, na medida do possível e conforme o caso, deve:

b) Tomar providências adequadas para assegurar que sejam devidamente levadas em conta as consequências ambientais de seus programas e políticas que possam ter sensíveis efeitos negativos na diversidade biológica.

Não apenas a manutenção da diversidade biológica, mas também a diversidade sociocultural e a capacidade das futuras gerações de brasileiros atenderem suas necessidades e atingir objetivos de desenvolvimento sustentável ficam mais distantes sem AAE. 


\section{Perspectivas}

Cabe perguntar por que a AAE não avança no Brasil. A resposta mais imediata talvez seja a falta de obrigação legal. O assunto vem sendo debatido há anos. Há projetos legislativos de alteração da Lei da Política Nacional do Meio Ambiente e leis já em vigor, como a lei paulista de mudanças climáticas.

O debate, no entanto, não parece suficientemente maduro. O entendimento que talvez seja dominante é o de que a AAE deveria ser exigida para planos e programas setoriais que resultam em projetos de alto potencial de impacto, sendo os setores de energia e de transportes os mais citados. Porém, a experiência com esses setores é que mesmo quando há inserção de preocupações socioambientais em etapas iniciais de planejamento, sempre que a carteira de projetos resultante inclui projetos de alto potencial de impacto, há embates, conflitos com comunidades locais e judicialização. Exemplo recente é a usina hidrelétrica de São Luiz do Tapajós, que teve sua licença prévia negada em julho de 2016. A decisão de avançar com esse projeto foi precedida não apenas dos estudos técnicos de inventário de potencial hidrelétrico, mas também de uma avaliação ambiental integrada e de estudos comparativos integrantes dos planos decenais de energia. Em paralelo, outros projetos desastrosos do ponto de vista socioambiental - tendo Belo Monte possivelmente como o pior exemplo - "passam" pelo licenciamento.

É, portanto, altamente incerta a contribuição que teria a obrigatoriedade de realização prévia de AAE para planos e programas de setores intrinsecamente conflituosos.

Por outro lado, há pouquíssima discussão sobre a potencial contribuição da AAE para planos e programas de setores menos controversos sob o ponto de vista ambiental, assim como para determinadas políticas públicas cujos efeitos ambientais podem ser difusos, mas significativos se tomados cumulativamente.

Exemplo do primeiro grupo são os programas habitacionais. Se a provisão de habitação popular a baixo custo é uma necessidade inquestionável, as formas de fazê-lo podem ter impacto ambiental não desprezível ou mesmo podem representar oportunidades de melhoria da qualidade ambiental ou de reversão de tendências de degradação. A interlocução com outras políticas públicas é uma contribuição potencial não explorada da AAE. A promoção da eficiência hídrica e energética em milhões de unidades habitacionais - ainda que ao custo de subsídios - teria repercussões positivas na indústria e no mercado de trabalho, contribuindo para a chamada "economia verde", ao mesmo tempo que para os objetivos de desenvolvimento sustentável. Um processo de AAE poderia ser um facilitador da integração de um programa ou política habitacional com outras políticas públicas. Assim, a AAE não seria facilitadora do licenciamento de cada conjunto habitacional, mas da formulação de PPP mais sustentáveis.

Outro caso é o de políticas macroeconômicas, cujos impactos socioambientais são difusos e mal conhecidos. Um exemplo são os subsídios à indústria automobilística, concedidos mediante redução de impostos. Motivados por ra- 
zões econômicas e pela manutenção de empregos industriais em toda a cadeia de fornecimento, os principais efeitos negativos dessas políticas são a deterioração da qualidade do ar em centros urbanos e o aumento da incidência de doenças respiratórias (Saldiva et al., 1994) - que, por sua vez, tem impactos econômicos secundários -, o aumento dos tempos de deslocamento e a perda de qualidade de vida. Tais políticas encontram amplo apoio em importantes setores empresariais, na mídia e em sindicatos, assim como na classe política, de modo que qualquer análise de suas consequências negativas sobre a saúde e a sociedade dificilmente teria chance de influenciar a decisão de adoção ou não. Entretanto, mitigações e compensações ao estilo daquelas resultantes dos estudos de impacto ambiental de projetos são perfeitamente factíveis. Possíveis mitigações dos impactos negativos de políticas de subsídio à indústria automobilística poderiam incluir reduções mais expressivas de impostos para ônibus e veículos, leves ou pesados, sobre trilhos, assim como para obras de infraestrutura de transporte público, incentivos para a construção de ciclovias, inclusive em áreas rurais, fortalecimento do sistema público de saúde, entre outras.

Tais PPP se desdobram em inúmeras ações de indivíduos, empresas e governos que na maioria das vezes não são objeto de qualquer forma de controle ambiental, mas cujos impactos acumulam-se no tempo e no espaço e podem ser mais significativos que os impactos de grandes projetos.

Há um vasto campo potencial para aplicação da AAE no país, em todos os níveis de governo e em todas as escalas territoriais. Por exemplo, as políticas urbanas e os planos diretores municipais podem ter influência sobre um modo de vida mais ou menos sustentável nas metrópoles e nas cidades médias (Fajersztajn; Veras; Saldiva, 2016). Incentivo ao adensamento ou tolerância ao espraiamento? Ocupação de várzeas e canalização de rios ou implantação de parques lineares ao longo de rios e córregos e de zonas de amortecimento de cheias? Renaturalização de rios e córregos degradados ou canalização? Restrição ou tolerância à impermeabilização do solo? Essas são algumas decisões estratégicas que têm claras implicações ambientais.

Assim, a AAE não deveria estar limitada a planos, programas ou políticas de setores cujos principais projetos já são objeto de licenciamento ambiental, mas voltada, primordialmente para políticas públicas cujas consequências socioambientais são hoje amplamente ignoradas dos tomadores de decisão e de amplos setores da sociedade.

Cabe aos pesquisadores e à comunidade de profissionais de avaliação de impactos demonstrar o valor da AAE e descobrir como tornar visível a contribuição da AAE. Organizações da sociedade civil e os setores dentro dos aparelhos de governo mais sensíveis à importância do planejamento de longo prazo podem evidenciar a contribuição da AAE (Marchioro et al., 2005). Produzir diagnósticos e relatórios é apenas um meio para se atingir determinada finalidade e o risco de burocratização e judicialização da AAE deveria ser evitado. 


\section{Conclusão}

Assim como a noção de desenvolvimento sustentável, o termo "avaliação ambiental estratégica" admite diferentes interpretações. Seu sentido e significado são potencialmente muito amplos e, se não forem definidos por meio de legislação, regulamentação ou outro tipo de acordo entre os interessados, seus objetivos, alcance e potencialidades podem facilmente ser objeto de discórdia.

A conceituação dominante no Brasil da AAE como a avaliação dos impactos de PPP, em contraposição - ou como um complemento - à AIA de projetos, é limitada. Vista de modo otimista, tal entendimento pode ser interpretado como requerendo que a $\mathrm{AAE}$ não esteja restrita ao atendimento de algum regulamento ou à mera preparação de um relatório, mas defendendo uma concepção ampla e renovada de planejamento, que leve em conta, de modo substancial, os impactos socioambientais, e não limite as possibilidades de desenvolvimento de uma região ou um país, permitindo que as futuras gerações possam dispor de recursos ambientais e culturais para atender às suas próprias necessidades. Por outro lado, essa mesma concepção aberta da AAE também pode significar que diferentes tipos de documentos e processos de planejamento, mesmo os mais tradicionais, sejam candidatos a receber o rótulo de AAE ou sejam apresentados sob essa nova roupagem, sem que haja mudança significativa de conteúdo.

Se não houver acordo sobre o alcance e os objetivos da AAE antes de se iniciar o processo, então é muito provável que a validação de suas conclusões encontre ceticismo ou mesmo resistência das partes interessadas, situação que prevalece hoje no país.

É conveniente relembrar alguns pontos básicos da AAE:

- é um processo e não um documento ou um relatório (embora o processo deva ser documentado, usualmente sob a forma de relatórios);

- é voltada para a tomada de decisões (estratégicas!!) e deve influenciá-las;

- deveria discutir as opções estratégicas quando estas ainda estão abertas, de modo a influenciar as decisões;

- não se limita à avaliação ex ante de PPP que se desdobram em projetos sujeitos ao licenciamento ambiental, mas se aplica também, e sobremaneira, a políticas públicas;

- não deveria ser usada para o que um bom EIA pode fazer, como avaliar alternativas de localização, avaliar impactos de grandes projetos e avaliar impactos cumulativos de grupos de projetos.

A avaliação ambiental estratégica pode contribuir para que decisões públicas e privadas sejam mais consistentes com as necessidades de um futuro comum sustentável. A verdadeira medida do sucesso da AAE será sua capacidade de influenciar as decisões e não a feitura de relatórios volumosos ou bem ilustrados. Seu objetivo é duplo: (1) identificar antecipadamente as consequências dos PPP a fim de evitar, atenuar ou compensar impactos adversos; e (2) influenciar dire- 
tamente o desenho de novos PPP que levem em conta seus impactos socioambientais e contribuam para o desenvolvimento sustentável, ajudando a formular as opções estratégicas. Em essência, a AAE não significa fazer "coisas diferentes, mas fazer as coisas diferentemente". ${ }^{2}$

Além disso, a AAE pode facilitar a integração de políticas, planos e programas dos diferentes ministérios ou secretarias - não raro formulados de maneira conflitante e implementados de forma fragmentada. Nesse sentido, a AAE possibilitaria o estudo da compatibilidade do PPP em análise com outros PPP governamentais, a chamada articulação horizontal. Esta característica se soma à potencialidade de articulação vertical - de política a plano, de plano a programas e de programas a projetos -, uma das facetas do seu papel facilitador do licenciamento ambiental.

Assim, não se trata de submeter planos, programas e políticas à $\mathrm{AAE}$, mas de usar a AAE para formulá-los e desenvolvê-los. Nessa distinção reside um ponto fundamental para a consolidação da AAE no país e sua possível institucionalização. É necessário encontrar fórmulas que permitam sua institucionalização - e possivelmente torná-la obrigatória para certas decisões - sem transformá-la em um obstáculo aos olhos dos tomadores de decisão e sem instituir um processo moroso, incompatível com os tempos de governo, ou burocrático e cheio de formalidades de procedimento, mas de pouco conteúdo substantivo. Uma cultura burocrática muito disseminada no país favorece a AAE como um estudo, um documento ou como procedimento: qual influência poderia ter sobre o processo decisório? A mesma que tem agora. Nula.

É preciso entender e evidenciar quais seriam as vantagens da AAE para as pessoas encarregadas da tomada de decisões, diferentemente das possíveis vantagens para a sociedade, estas já conhecidas. É possivelmente esse o ponto fulcral para o sucesso da AAE. É preciso encontrar formas de superar a desconfiança que a classe política e os tomadores de decisão em todos os níveis de governo têm de uma ferramenta ou de um processo que eles percebem como algo que reduz sua margem de discrição e seu poder de decisão. Inevitavelmente, a AAE exige maior transparência e melhor governança. É esse o grande obstáculo à sua adoção no Brasil.

\section{Notas}

1 "Avaliação Ambiental Estratégica e sua Aplicação no Brasil", texto preparado como referência para o debate "Rumos da Avaliação Ambiental Estratégica no Brasil", realizado em 9 de dezembro de 2008 no Instituto de Estudos Avançados da Universidade de São Paulo. Disponível em <http://www.iea.usp.br/publicacoes/textos/aaeartigo.pdf>.

2 Fórmula do Prof. Kin-Che Lam, da Universidade Chinesa de Hong Kong. 


\section{Referências}

AHMED, K.; MERCIER, J. R.; VERHEEM, R. Strategic Environmental Assessment - Concept and Practice. World Bank Environment Strategy Notes, v.14, p.1-4, 2005.

BASTOS, M. M. A avaliação ambiental estratégica no contexto brasileiro: efetividade e desafios jurídico-institucionais. São Paulo, 2015. Dissertação (Mestrado) - Escola de Direito de São Paulo, Fundação Getulio Vargas. São Paulo, 2015.

BISWANGER, H. P. Brazilian Policies that Encourage Deforestation in the Amazon. World Bank Environment Department Working Paper, v.16, n.11-24, 1989.

DALAL-CLAYTON, B.; SADLER, B. Strategic environmental assessment: a sourcebook and reference guide to international experience. London: IIED, 2004. 385p.

EGLER, P. C. G. Perspectivas de uso no Brasil do processo de avaliação ambiental estratégica. Parcerias Estratégicas, v.11, p.175-90, 2001.

FAJERSTAJN, L.; VERAS, M.; SALDIVA, P. H. N. Como as cidades podem favorecer ou dificultar a promoção da saúde de seus moradores? Estudos Avançados, v.30, n.86, p.7-27, 2016.

GORELICK, S. Small is beautiful, big is subsidised. How our taxes contribute to social and environmental breakdown. Devon: International Society for Ecology and Culture, 1998. 56p.

KLÄNE, C.; ALBRECHT, E. Purpose and background of the European SEA Directive. In: SCHMIDIT, M.; JOÃO, E.; ALBRECHT, E. (Org.) Implementing strategic environmental assessment. Berlin: Springer-Verlag, 2005. p.15-29.

MAHAR, D. Government policies and deforestation in Brazil's Amazon Region. World Bank Environment Department Working Paper, v.7, n.1-42, 1988.

MARCHIORO, G. B. et al. Avaliação dos impactos da exploração e produção de hidrocarbonetos no Banco dos Abrolhos e adjacências. Megadiversidade, v.2, n.1, p.225-310, 2005.

MARGATO, V.; SÁNCHEZ, L. E. Quality and outcomes: a critical review of Strategic Environmental Assessment in Brazil. Journal of Environmental Assessment Policy and Management, v.16, n.2, p.1450011, 2014.

MMA - MINISTÉRIO DE MEIO AMBIENTE. Avaliação Ambiental Estratégica. Brasília: MMA, 2002. 91p.

MONTAÑO, M.; MALVESTIO, A.; OPERMANN, P. Institutional Learning by SEA Practice in Brazil. UVP Report, v.27, n.4+5, p.201-6, 2013.

MONTAÑO, M.; OPERMANN, P.; MALVESTIO, A. C.; SOUZA, M. P. Current state of the SEA system in Brazil: a comparative study. Journal of Environmental Assessment Policy and Management, v.16, n.2, p.1450022, 2014.

OCED - ORGANIZAÇÃO DE COOPERAÇÃO E DESENVOLVIMENTO ECONÔMICO. Aplicação da Avaliação Ambiental Estratégica: Guia de Boas Práticas na Cooperação para o Desenvolvimento. Paris: OECD Publishing, 2012.

PELLIN, A.; LEMOS, C. C.; TACHARD, A.; OLIVEIRA, I. S. D.; SOUZA, M. P. Avaliação ambiental estratégica no Brasil: considerações a respeito do papel das agências multilaterais de desenvolvimento. Engenharia Sanitária e Ambiental, v.16, n.1, p.27-36, 2011. 
PIRES, S. H. et al. New Aspects of Impact Assessment in the Planning Process: the Case of Amazon Transmission System. Impact Assessment, v.11, n.3, p.321-32, 1993.

RAMOS, T. B.; MONTAÑO, M.; MELO, J. J.; SOUZA, M. P.; LEMOS, C. C.; DOMINGUES, A. R.; POLIDO, A. Strategic environmental assessment in higher education: Portuguese and Brazilian cases. Journal of Cleaner Production, v.106, p.222-8, 2015.

RETIEF, F. A Performance Evaluation of Strategic Environmental Assessment (SEA) Processes Within the South African Context. Environmental Impact Assessment Review, v.27, n.1, p.84-100, 2007.

ROODMAN, D. M. Paying the Piper: Subsidies, Politics, and the Environment. Worldwatch Paper, v.133, p.1-80, 1996.

SALDIVA, P. H. N. et al. Association between Air Pollution and Mortality Due to Respiratory Diseases in Children in São Paulo, Brazil: A Preliminary Report. Environmental Research, v.65, n.2, p.218-25, 1994.

SÁNCHEZ, L. E.; HENNIES, W. T.; ESTON, S. M.; MENEZES, C. B. Cumulative impacts and environmental liabilities in the Santa Catarina Coalfield in Southern Brazil. In: Third Int. Conf. Environmental Issues and Waste Mngt in Energy and Mineral Industries, Perth, Proceedings, p. 75-85, 1994.

SÁNCHEZ, L. E.; CROAL, P. Environmental impact assessment, from Rio-92 to Rio+ 20 and beyond. Ambiente e Sociedade, v.15, n.3, p.41-54, 2012.

SÁNCHEZ, L. E.; SILVA-SÁNCHEZ, L. E. Tiering Strategic Environmental Assessment and Project Environmental Impact Assessment in Highway Planning in São Paulo, Brazil. Environmental Impact Assessment Review, v.28, p.515-22, 2008.

SLOOTWEG, R.; KOLHOFF, A.; VERHEEM, R.; HÖFT, R. Biodiversity in EIA \& SEA - Background Document to CDB Decision VIII/28: Voluntary Guidelines on Biodiversity-Inclusive Impact Assessment. Utrecht: Commission for Environmental Assessment, 2006. 79p.

STEINEMANN, A. Improving alternatives for environmental impact assessment. Environmental Impact Assessment Review, v.21, p.3-21, 2001.

TEIXEIRA, I. M. V. O uso da avaliação ambiental estratégica no planejamento da oferta de blocos para exploração e produção de petróleo e gás no Brasil: uma proposta. Rio de Janeiro, 2008. Tese (Doutorado) - Coppe, Universidade Federal do Rio de Janeiro. Rio de Janeiro, 2008. 308p.

TETLOW, M. F.; HANUSH, M. Strategic environmental assessment: the state of the art. Impact Assessment and Project Appraisal, v.30, n.1, p.15-24, 2012.

THÉRIVEL, R.; WILSON, E.; THOMPSON, S.; HEANEY, PRITCHAR, D. Strategic Environmental Assessment. London: Earthscan, 1992. 181p.

WATHERN, P.; YOUNG, S. N.; BROWN, I. W.; ROBERTS, D. A. Assessing the Impacts of Policy: a Framework and an Application. Landscape and Urban Planning, v.14, p.321-30, 1987.

WCED - WORLD COMMISSION ON ENVIRONMENT AND DEVELOPMENT. Our Common Future. Oxford: Oxford University Press, 1987. 400p. 
RESUMO - Embora discutida em certos círculos acadêmicos e governamentais há mais de vinte anos, a Avaliação Ambiental Estratégica (AAE) pouco avança no país. São conhecidos cerca de $40 \mathrm{AAE}$, mas seus resultados são pífios, se considerada sua influência sobre processos decisórios. A AAE não deveria estar limitada a planos, programas ou políticas de setores cujos principais projetos já são objeto de licenciamento ambiental, mas voltada primordialmente para políticas públicas cujas consequências socioambientais são hoje amplamente ignoradas, a exemplo das macroeconômicas. Para avançar, é preciso evidenciar as vantagens da AAE para os tomadores de decisão e encontrar formas de superar a desconfiança que tem os políticos, em todos os níveis de governo, de um processo que percebem como redutor de sua margem de discrição e poder decisório. Inevitavelmente, a AAE exige maior transparência e melhor governança. Esse é o grande obstáculo à sua adoção no Brasil.

Palavras-CHAVE: Planejamento, Políticas públicas, Impactos socioambientais, Objetivos de desenvolvimento sustentável.

ABSTRACT - Strategic Environmental Assessment (SEA) has been discussed for many years in Brazil. Despite the fact that about 40 such assessments have been conducted so far, their outcomes have been piddling if we consider their actual influence in decision-making. SEA should not be limited to plans, programs or policies in economic sectors where major projects already require mandatory environmental impact assessments, but rather aimed primarily at public policies whose social and environmental consequences are barely known or largely ignored, such as macroeconomic policies. The value of SEA to decision-makers must be demonstrated to overcome distrust, especially among politicians who perceive SEA as reducing their discretionary power. Inevitably, SEA requires more transparency and better governance. That is biggest hurdle to its effective implementation in Brazil.

KErWorDs: Planning, Public policies, Socio-environmental impacts, Sustainable development objectives.

Luis Enrique Sánchez é professor titular da Escola Politécnica da Universidade de São Paulo. @-lsanchez@usp.br

Recebido em 31.8.2016 e aceito em 24.10.2016.

IEscola Politécnica, Universidade de São Paulo, São Paulo / São Paulo, Brasil. 